\title{
Resistência parasitária em helmintos de eqüídeos e propostas de manejo
}

\author{
Parasite resistance on helminths of equids and management proposal's
}

\author{
Marcelo Beltrão Molento ${ }^{1}$
}

\section{- REVISÃO BIBLIOGRÁFICA -}

\section{RESUMO}

Os eqüinos apresentam uma grande variedade de parasitas em sua fauna helmíntica, e algumas espécies/ gêneros são de relevada importância, como: Parascaris equorum, Anoplocephala perfoliata, Oxyuris equi, Cyathostomum spp. e Strongylus spp. O controle destas infecções depende principalmente da utilização de produtos antiparasitários de forma supressiva ou estratégica e, em menor escala, de forma curativa. O tratamento supressivo é o fator mais importante na promoção da seleção de organismos resistentes, prejudicando a sustentabilidade de qualquer programa sanitário. As formas de detecção da resistência parasitária são onerosas e as mais comuns expressam resultados imprecisos. Entretanto, estas técnicas servem para monitorar a evolução e determinar os organismos envolvidos. A combinação de drogas é uma ferramenta que deve ser utilizada com muita cautela, pois esta alternativa não garante uma redução significativa de organismos resistentes aos compostos envolvidos. O objetivo deste artigo é apresentar formas de planejamento que auxiliem a melhorar a condição sanitária, o bem-estar dos animais e preserve o efeito tóxico dos produtos antiparasitários.

Palavras-chave: eqüinos, helmintos, resistência, compostos antiparasitários.

\section{ABSTRACT}

Equines harbour a variety of parasitic organisms on their helminth fauna and there are a few species/genus of interest, such as: Parascaris equorum, Anoplocephala perfoliata, Oxyuris equi, Cyathostomum spp. and Strongylus spp. The control of these infections relies mostly on the suppressive or strategic usage of antiparasitic compounds, and to a less extent on curative/salvage treatments. Suppressive treatment is the most important factor regarding the selection of resistant organisms, causing the impairment of sanitary programs. Detection methods of parasite resistance are expensive and the most common ones express variable results. Although, these techniques allow monitoring the evolution and the determination of which organisms are involved. Drug combination is a toll that should be used with caution, because it may not reduce the presence of resistant organisms to the compounds involved. The objective of this article is to demonstrate control alternatives that would contribute to sanitary management, to improve animal welfare and to preserve the toxic effect of the antiparasitic products.

Key words: equines, helminths, resistance, antiparasitic compounds.

\section{INTRODUÇÃO}

As formas de criação dos eqüídeos favorecem a grande incidência de infecções parasitárias, já nas primeiras semanas de vida. A fauna parasitária é vasta e compreende várias famílias/ gêneros distintas, entre elas: os Pequenos estrôngilos

${ }^{1}$ Setor de Doenças Parasitárias, UFSM. Departamento de Medicina Veterinária, Universidade Federal do Paraná, Rua dos Funcionários, 1540, 80035-050, Curitiba, PR, Brasil. E-mail: molento@ufpr.br. Autor para correspondência. 
ou cyathostominos: Cyathostomum spp., Triodontophorus spp., Cylicostephanus spp., os Grandes estrôngilos: Strongylus vulgaris, S. equinus, S. edentatus e ainda, Parascaris equorum, Oxyuris equi, Strongyloides westeri, Trichostrongylus axei, Gasterophilus spp., Habronema spp., Dictyocaulus arnfield, Anoplocephala spp. Conforme BARBOSA et al. (2001) os cyathostominos são os parasitas mais prevalentes em animais jovens (12 a 14 meses) e adultos (acima de 60 meses). Entretanto a distribuição das espécies tem grande variação nestes faixas etárias.

Os helmintos podem causar desde um pequeno desconforto abdominal até episódios fulminantes de cólicas e morte. Dados de campo sugerem que os eqüinos adquirem resistência aos pequenos estrôngilos com a idade, verificados através da redução da carga parasitária e a contagem de ovos nas fezes. Esta resposta é lenta e inconsistente na maioria dos animais e não tem relação com a intensidade do contato parasitário anterior (KLEI \& CHAPMAN, 1999). No entanto, a imunidade adquirida só será desencadeada quando ocorrer o contato do hospedeiro com o parasita.

O controle da parasitose é fundamental, pois resulta em um melhor desempenho dos animais, especialmente quando estão com elevada carga animal por área. A forma de controle adotado na maioria dos criatórios utiliza exclusivamente os compostos antiparasitários por sua praticidade e eficiência, por sua ótima relação custo-benefício e pela facilidade de aquisição. Dentre os compostos disponíveis, existem quatro grupos químicos distintos que são os mais utilizados: os benzimidazóis (ex: albendazole e oxibendazole), as pirimidinas e imidazotiazóis (ex: pamoato de pirantel e levamisole) e o grupo das lactonas macrocíclicas (ex: ivermectina e moxidectin). A grande diferença entre os grupos químicos está no seu mecanismo de ação diferenciado e nas formas de eliminação parasitária (MARTIN, 1997). Vale lembrar, no entanto, que nenhum composto antiparasitário é eficaz contra todos os estádios de desenvolvimento dos parasitas de eqüinos. Neste particular, somente a moxidectina tem efeito moderado contra larvas encistadas de terceiro e quarto estádio e nenhum efeito contra larvas em hipobiose (MONAHAN et al., 1996).

Em relação à utilização dos medicamentos, a freqüência de sua utilização pode ser de forma supressiva: tratamentos a cada 4-8 semanas, estratégica: tratamentos regulados pelas condições climáticas da região e o possível aumento do número de parasitas no animal, ou curativa: tratamentos quando o animal apresenta alta contagem de ovos nas fezes ou sinais clínicos (SANGSTER, 2003). Sabe-se também, que a alternância entre os quatro grupos químicos descritos acima é freqüente, ocorrendo várias vezes ao ano (ALMEIDA et al., 2004). Esta situação é complementada pela falta de monitoramento da eficácia dos produtos utilizados, o que dificulta uma melhor avaliação do Médico Veterinário no sucesso ou não do programa antiparasitário em execução.

\section{O que é a resistência parasitária?}

A resistência parasitária é um fenômeno pelo qual uma droga não consegue manter a mesma eficácia contra os parasitas, se utilizada nas mesmas condições, após um determinado período de tempo (CONDER \& CAMPBELL, 1995).

O diagnóstico é positivo para "resistência” quando uma determinada droga que apresentava redução da carga parasitária acima de 95\% decresce a nível inferior a este valor contra o mesmo organismo depois de determinado período (CONDER \& CAMPBELL, 1995). O aparecimento da resistência parasitária é praticamente inevitável e esta característica é transferida para as próximas gerações. No entanto, a sua manifestação é condicionada à presença de indivíduos que apresentem o gene que confere para a resistência. $\mathrm{O}$ tema relativo à genética da resistência será abordado abaixo.

A eficácia das drogas diminui consideravelmente devido a este caráter seletivo, favorecendo a permanência de organismos resistentes e a eliminação de indivíduos susceptíveis. A população resistente não é alterada com o tratamento antiparasitário, ocorrendo então, uma mudança da característica genética da população. O intervalo para que este fenômeno se inicie, dependerá da espécie do parasita, da pressão de seleção exercida pela droga e da frequência do tratamento nos eqüinos.

\section{Refugia: população susceptível}

Refugia é um termo utilizado para definir toda a população parasitária que não foi exposta ao processo de seleção pelas drogas, permanecendo com sua característica primária de susceptibilidade (VAN WYK, 2001). Este grupo de parasitas compreende as formas livres no ambiente e as larvas e adultos no local de parasitismo. Porém, após um primeiro tratamento dito eficaz, a progênie dos parasitas sobreviventes irá se desenvolver junto com a refugia. Então o tamanho da população em refugia pode ter um papel fundamental na manutenção da eficácia das drogas, retardando o processo de seleção. Deve-se ter em mente que refugia é diferente do que se conhece como estoque de larvas na pastagem. 
Causas predisponentes ao aparecimento da resistência parasitária

Tratamento supressivo - curto intervalo entre tratamentos: $\mathrm{O}$ tratamento que visa eliminar os parasitas no hospedeiro antes que este complete seu ciclo de vida, é uma estratégia que só pode ser indicada após a comprovação da inexistência da resistência parasitária. Principalmente, porque os indivíduos sobreviventes destes tratamentos estarão aptos a suportar qualquer esquema de tratamento e assim contaminarão na pastagem com uma nova e vigorosa população resistente. Deve-se propor intervalos que permitam que a população susceptível complete seu ciclo biológico, anulando o processo de seleção química.

Tratamento estratégico: É utilizado quando o número de larvas na pastagem se encontra reduzido. Porém, muito embora esta estratégia possa maximizar os efeitos do tratamento, também poderá fragilizar a população em refugia, favorecendo indivíduos resistentes.

Medicamentos de longa persistência: $\mathrm{O}$ período de persistência das drogas tem ampla variação entre os compostos e exerce grande influência no processo de seleção parasitária. Esta característica é mais importante do que a concentração tóxica atingida pelo composto. A seleção devido à persistência/cauda ou tail selection, pode ser observada na figura 1 . A concentração da droga acima do limite A promove a eliminação de todos os parasitas, e a concentração da droga abaixo de B só elimina a população susceptível.
O período de tempo que a concentração das drogas permanece entre $\mathrm{A}$ e $\mathrm{B}$, resulta no aumento da seleção das larvas recém-ingeridas e presentes na mucosa (SANGSTER, 1999). A administração de drogas com longa persistência, como as macrolactonas faz com que a concentração residual mínima, abaixo de B, não permita o estabelecimento e a reprodução de indivíduos susceptíveis, favorecendo a seleção parasitária e prejudicando sobremaneira a população em refugia (MOLENTO et al., 2004).

Uso da combinação de compostos: A utilização desta estratégia apresenta o maior grau de eliminação parasitária, podendo inclusive manter altos índices de eficácia por períodos prolongados. No entanto, as formulações devem apresentar eficácia elevada quando testados isoladamente. Existem várias associações de bases químicas, porém em eqüinos, a combinação mais freqüente é a associação de uma lactona macrocíclica com o praziquantel (Tabela 1).

Uso de doses baixas por períodos prolongados: DI PIETRO (1992) sugeriu que a utilização de uma dose abaixo da dose terapêutica, administrada diariamente, poderia promover maior vantagem quando comparada ao tratamento convencional. O objetivo do uso diário de medicação antiparasitária em subdosagens seria o de prevenir a infecção e migração dos parasitas, e ainda remover parasitas adultos. Esta forma de manejo foi iniciada antes da metade do século XX, quando TODD et al. (1949) sugeriram a utilização da fenothiazina por 21 dias/mês. No entanto este protocolo foi interrompido

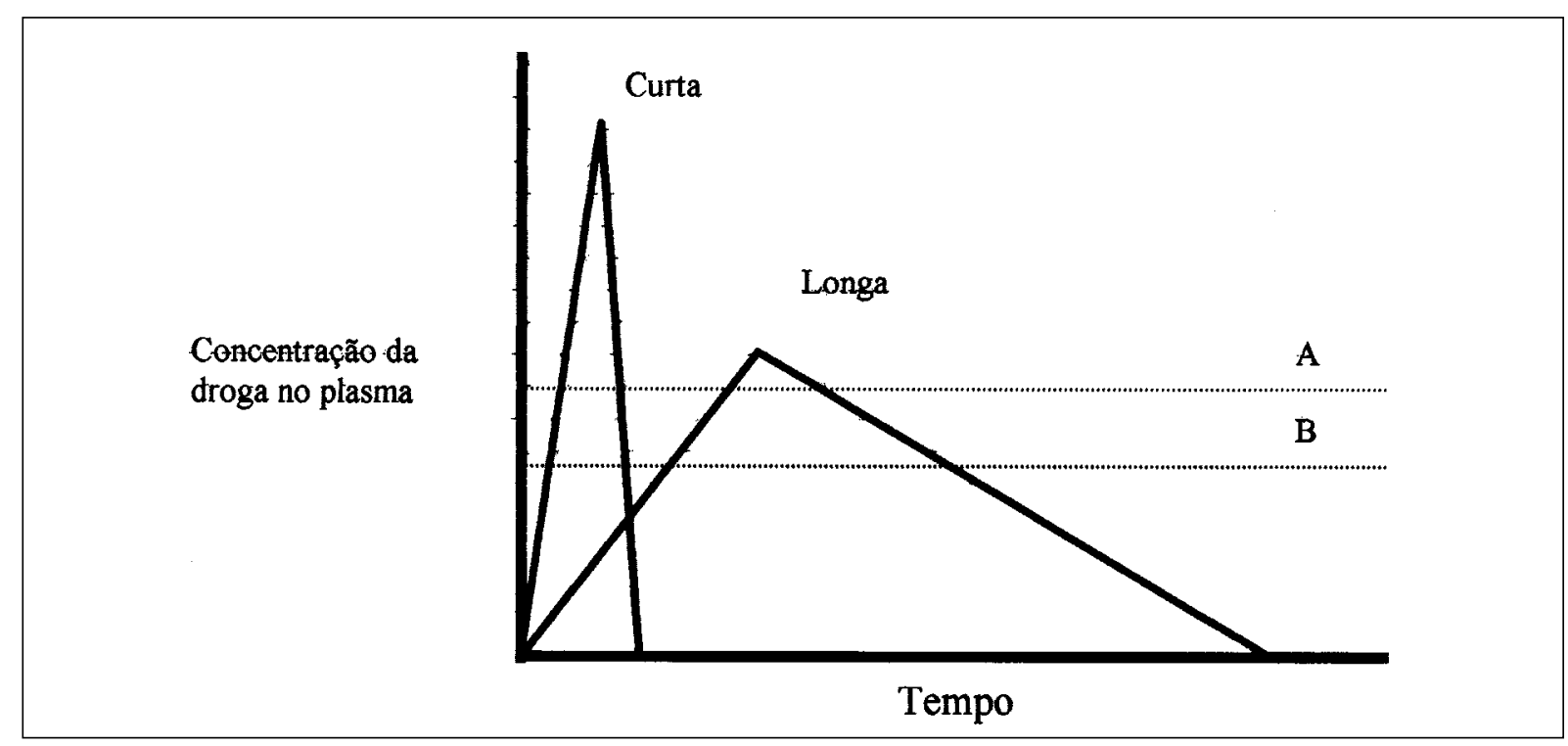

Figura 1 - Desempenho típico de compostos que apresentam cauda curta (benzimidazóis) e cauda longa (lactonas macrocíclicas) (SANGSTER 1999). Reprodução da figura com permissão da Elsevier Science.

Ciência Rural, v.35, n.6, nov-dez, 2005. 
Tabela 1 - Eficácia da combinação de compostos antiparasitários, formulação, tamanho dos grupos testados, dias de avaliação póstratamento, organismos parasitários e lista de referências.

\begin{tabular}{|c|c|c|c|c|c|c|}
\hline Combinação & Formulação & ${ }^{\mathrm{a}} \mathrm{N}$ grupo & Exame $\mathrm{PT}^{\mathrm{b}}$ & Espécie/gênero & Eficácia (\%) & Referência \\
\hline \multirow{5}{*}{ IVM 1,25\% + PZT 15,62\% } & \multirow{5}{*}{ Gel - PO } & \multirow{5}{*}{6} & \multirow{5}{*}{$1,3,5,7,14^{\mathrm{c}}$} & Gasterophilus & 100 & \multirow{5}{*}{ ENGRACIA et al.1999 } \\
\hline & & & & Oxyuris equi & 99,93 & \\
\hline & & & & Cyathostomum & 99,99 & \\
\hline & & & & Anoplocephala perfoliata & 100 & \\
\hline & & & & Habronema & 100 & \\
\hline IVM 1,87\% + PZT 14,03\% & Gel - PO & 16 & $\begin{array}{l}14,21,28,35,42 \\
49,56,63,70^{\mathrm{e}}\end{array}$ & $\begin{array}{l}\text { Cyathostominae } \\
\text { Gyalocephalus sp. } \\
\text { Triodontophorus sp. }\end{array}$ & Acima de 90 & MERCIER et al. 2001 \\
\hline IVM 1,2\% + PZT 15\% & Gel - PO & 6 & $7^{c}$ & Anoplocephala perfoliata & 100 & TANCREDI et al.2001 \\
\hline IVM 1,55\% + PZT 7,55\% & Gel - PO & $\begin{array}{l}8,16 \\
28\end{array}$ & $7,8,9,14,15,16$ & $\begin{array}{l}\text { Strongylideos } \\
\text { Anoplocephala sp. } \\
\text { Paranoplocephala sp. }\end{array}$ & Acima de 98 & REHBEIN et al. 2003 \\
\hline \multirow{2}{*}{ IVM 0,2mg/k + PZT 1,5mg/kg } & \multirow{2}{*}{ Gel - PO } & \multirow{2}{*}{62} & \multirow{2}{*}{$2,8,10^{\mathrm{d}}$ semanas } & Anoplocephala perfoliata & 100 & \multirow{2}{*}{ BARRETT et al. 2004} \\
\hline & & & & Strongylus sp. & 100 & \\
\hline \multirow{2}{*}{ IVM 1,25\% + PZT 15,62\% } & \multirow{2}{*}{ Gel - PO } & \multirow{2}{*}{6} & \multirow{2}{*}{$14^{\mathrm{c}}$} & Nematoda & 100 & \multirow{2}{*}{ TANCREDI et al.2004 } \\
\hline & & & & Cestoda & 100 & \\
\hline \multirow{6}{*}{$\mathrm{ABM} 1,25 \%+\mathrm{PZT} 15,62 \%$} & \multirow{6}{*}{ Gel - PO } & \multirow{6}{*}{6} & \multirow{6}{*}{$1,3,5,7,14^{\mathrm{c}}$} & Parascaris equorum & 100 & \multirow{6}{*}{ SABATINI et al. 1999} \\
\hline & & & & Oxyuris equi & 100 & \\
\hline & & & & Triodontophorus & 100 & \\
\hline & & & & Anoplocephala perfoliata & 100 & \\
\hline & & & & Strongylus edentatus & 57,5 & \\
\hline & & & & Cyathostomum & 99,99 & \\
\hline \multirow{2}{*}{$\mathrm{ABM} 1,25 \%$ + PZT 15,62\% } & \multirow{2}{*}{ Gel - PO } & \multirow{2}{*}{6} & \multirow{2}{*}{$14^{\mathrm{c}}$} & Nematoda & 100 & \multirow{2}{*}{ TANCREDI et al.2004 } \\
\hline & & & & Cestoda & 100 & \\
\hline
\end{tabular}

a: PO: Per Os, administração via oral.

b: avaliação pós-tratamento, PT (necropsia ou exame de fezes).

c: dia PT em que foi realizada necropsia parasitológica para obtenção de parasitas adultos e/ou formas imaturas.

$\mathrm{d}$ : contagem de ovos nas fezes durante 10 semanas.

e: OPG e coprocultura em todos os intervalos.

IVM: Ivermectina, ABM: Abamectina, PET: Praziquantel.

após o aparecimento de efeitos colaterais indesejáveis. Somente com LYONS et al. (1974) é que pamoato de pirantel foi indicado em uso diário na concentração de $6,6 \mathrm{mg} \mathrm{kg}^{-1}$ para controle de cestodas e nematodas. Os autores determinaram que este procedimento poderia ser utilizado durante os períodos com altas taxas de translação, sem o aparecimento da resistência. Entretanto, KAPLAN et al. (2003) sugeriram que a existência de resistência em $48 \%$ das propriedades de criação de cavalos no Sudoeste dos Estados Unidos, seria devido à utilização de baixas concentrações do pamoato de pirantel em forma de uso diário por períodos prolongados.

Como ocorre o processo de seleção parasitária?

A freqüência de utilização dos compostos antiparasitários é o principal fator responsável pelo desencadeamento do processo de seleção. Este aspecto ocorre de maneira gradativa e acredita-se que quanto maior a eficácia da droga, mais acentuado seja o início do processo de seleção por organismos homozigoto-resistentes (BARGER, 1995).

SUTHERST \& COMINS (1979) descrevem três componentes da gênese da resistência. No início, como um evento ao acaso, existe o estabelecimento da resistência, que é influenciado pelo tamanho e pela diversidade da população parasitária. Não se tem controle quanto ao estabelecimento da resistência nesta fase. Segue-se então o desenvolvimento da resistência que é agravado com o uso de agentes selecionadores, como os compostos químicos. Caso este processo seja contínuo e a população resistente se encontre em vantagem numérica, ter-se-á então a manifestação da resistência como um problema visível.

Teoricamente, uma população é composta por indivíduos, na sua maioria, homozigoto susceptível (SS), poucos indivíduos heterozigotos (SR e/ou RS) e uma parcela mínima de homozigoto resistente (RR). A 
mínima presença de indivíduos RR ou dominantes (0,01\%) permite o início do processo de seleção, logo após o primeiro contato com um composto antiparasitário. Uma vez detectada resistência para este composto, muda-se a base química e inicia-se então o tratamento dos animais com um novo produto, observando-se um segundo processo de seleção independente. Desta forma, após um certo período de tempo, a população será composta por indivíduos que apresentam resistência a todas as famílias de drogas (resistência múltipla), resultando no esgotamento de todo o arsenal químico.

Quando a resistência é controlada por um gene (monogênica), o processo de seleção é rápido. Este é o caso da resistência aos benzimidazóis, com a mutação de um único aminoácido no gene da subunidade alfa da Beta-tubulina em eqüinos. Porém quando ela é regulada por mais de um gene (poligênica), o processo pode ser mais lento. O exemplo neste caso é o desenvolvimento da resistência contra as lactonas macrocíclicas que envolvem os Canais de Cloro potencializados pelo Glutamato, a subunidade alfa da Beta-tubulina e a fosfo-glicoproteína que atua retirando a droga da membrana da célula nervosa (XU et al. 1998; PRICHARD, 2001).

Na figura 2, observa-se uma alta correlação entre a eficácia dos compostos e o período pré-patente (PPP) dos organismos, favorecendo a seleção para a resistência (região escura na parte superior esquerda e a área entre as linhas sólidas). Os círculos enumerados representam as variações entre o PPP para cada espécie. O local onde se encontram, significa a susceptibilidade das espécies de cyathostominos frente às drogas. Quando, por exemplo, se combina uma espécie com PPP curto e um composto com eficácia acima de 90\%, esta espécie parasita sofrerá grande pressão de seleção (círculo 1). Espécies nos círculos 2 e 3 terão menor seleção e lento desenvolvimento da resistência. As espécies 4, 5 e 6 serão beneficiadas e podem nunca sofrer esta pressão. Parasitas resistentes que pertencem a uma espécie com PPP acima de dezoito semanas apresentam pouca vantagem reprodutiva, tendo seus genes diluídos na população (SANGSTER, 1999).

Métodos para avaliar a eficácia dos anti-helmínticos

O monitoramento da eficácia das drogas nos Haras e Fazendas de criação é uma rotina pouco utilizada ou até mesmo inexistente. Na maioria dos casos, a resistência é determinada após a observação empírica da pouca eficácia da medicação utilizada. Para dificultar ainda mais a situação, um dos maiores entraves encontrados para estimar o fator de resistência é a falta de métodos sensíveis para quantificá-la. Desta forma, as estimativas de prevalência realizadas com as atuais técnicas laboratoriais de rotina são, na melhor das hipóteses, subestimadas.

O teste controlado e o teste crítico são amplamente aplicados por indústrias farmacêuticas para determinar a eficácia dos compostos contra várias

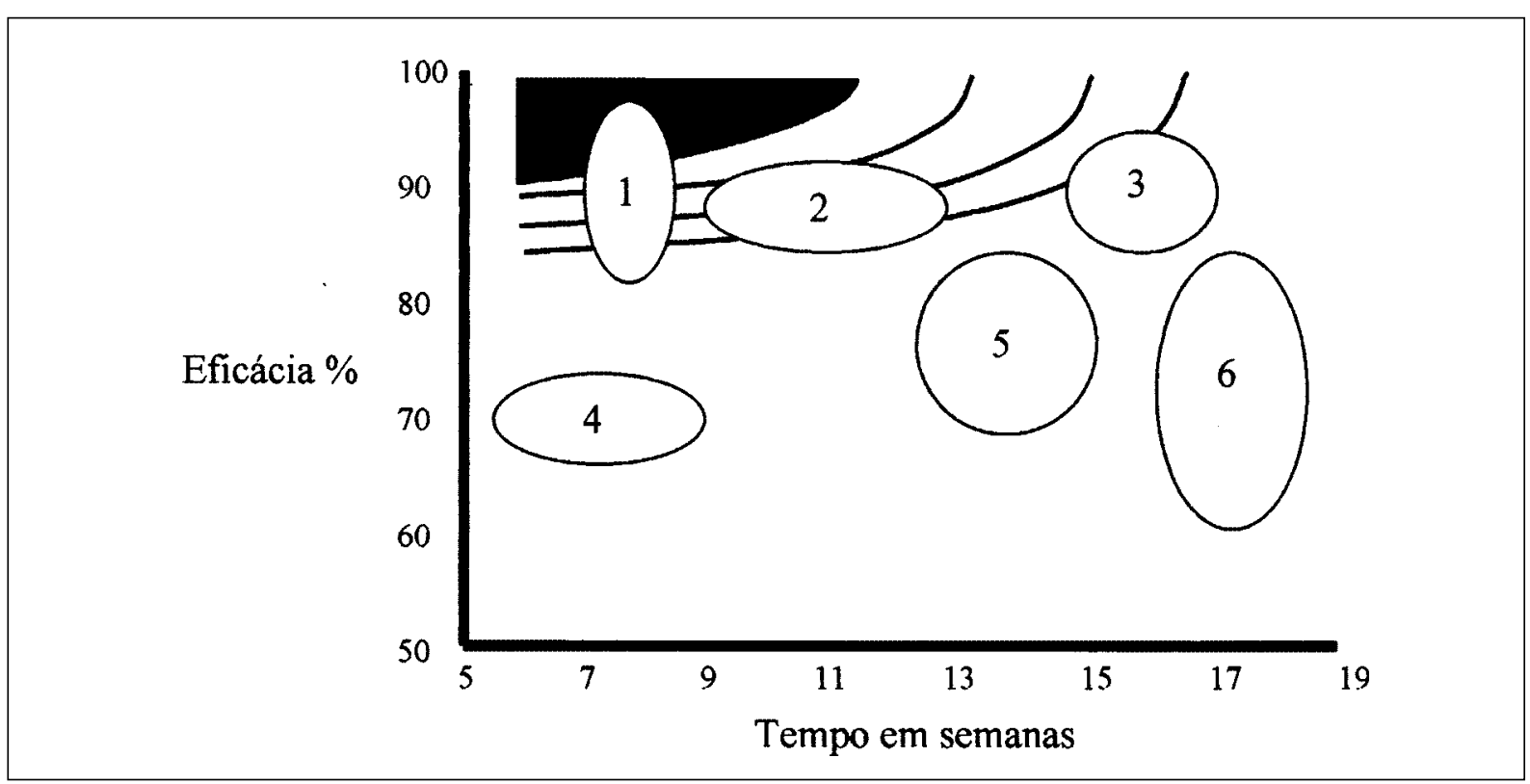

Figura 2 - Esquema hipotético da seleção para resistência em cyathostominos (SANGSTER 1999). Reprodução da figura com permissão da Elsevier Science.

Ciência Rural, v.35, n.6, nov-dez, 2005. 
espécies de parasitas de eqüinos. O teste controlado compara o grupo controle com o grupo tratado, já o teste crítico compara os resultados de um mesmo grupo, pré e pós-tratamento. Em ambos os casos, todos os animais devem ser necropsiados para contagem de adultos e larvas nos órgãos parasitados (DUNCAN et al., 2002).

A técnica mais utilizada para avaliar a eficácia dos produtos comerciais é o teste de contagem de ovos ou larvas por grama de fezes (OPG ou LPG) pré e pós-tratamento, também chamado de teste clínico. Muito embora o resultado deste teste não seja consistente, podendo apresentar uma variação acima de $20 \%$, pode-se indiretamente determinar a presença da resistência quando a eficiência de determinado produto esteja abaixo de 95\%. Para se calcular a eficácia dos compostos, é necessário utilizar a fórmula descrita por COLES et al. (1992):

\% Eficácia = média OPG grupo controle - média OPG grupo tratado $\times 100$ média OPG grupo controle

PRESLAND et al. (2004) determinaram que o método FECPAK pode ser utilizado para se obter resultados mais precisos que o teste de McMaster modificado (OPG). A técnica segue o princípio de flutuação-diluição e elimina a possibilidade de resultados falso-negativos.

Espera-se que, em um futuro próximo, seja possível desfrutar de técnicas moleculares para a determinação antecipada e precisa (variação abaixo de 1\%) da resistência parasitária na rotina laboratorial (PRICHARD, 2001).

Comprovação da resistência parasitária

Os primeiros relatos de resistência em eqüinos foram determinados em pequenos estrôngilos frente ao benzimidazole, a piperazina e ao pamoato de pirantel (CHAPMAN et al., 1996). YOUNG et al. (1999) também determinaram a redução da eficácia do fenbendazole (32\%) contra cyathostominos. O pamoato de pirantel, benzimidazóis, ivermectin e moxidectin obtiveram média de $42,3 \%$, abaixo de $50 \%$, 98 e 100\%, respectivamente, na região de Curitiba, PR (MERCADANTE et al., 1997). A coprocultura revelou a presença de $85 \%$ das larvas sendo de pequenos estrôngilos, $12 \%$ de grandes estrôngilos e 3\% de Trichostrongylus axei. Em Santa Maria, RS, ALMEIDA et al. (2004) determinaram o número de ovos de helmintos por grama de fezes (OPG), os gêneros parasitários, a correlação entre a freqüência de tratamento antiparasitário, a idade dos animais e a eficácia do controle parasitário em 65 eqüinos Puro Sangue de Corrida residentes no Jockey Clube Santa- mariense. Entre os animais, 36,9\% apresentaram OPG positivo, com prevalência de: Trichostrongylus spp. (66,6\%), Strongylus spp. (50\%), Parascaris spp. (12,5\%) e Strongyloides spp. (4,2\%). Constatou-se que $27,3 \%$ dos potros ( 1 a 3 anos) e $45,4 \%$ dos adultos (a partir de 4 anos) apresentaram OPG positivo. Embora não significativa, foi observada correlação positiva entre o aumento do intervalo entre tratamentos (1 até 12 meses) e o aumento da freqüência de animais positivos. Porém 54,6\% dos potros e 50\% dos adultos apresentaram Strongylus spp. (7,4\%), Trichostrongylus spp. $(11,1 \%)$ e Strongyloides spp. (3,7\%) mesmo recebendo tratamento anti-helmíntico em intervalos de 30 a 60 dias. A informação obtida foi que ivermectina $(44,4 \%)$, doramectina $(11,1 \%)$ e oxibendazole $(22,2 \%)$ foram os compostos utilizados no último tratamento e em esquema alternado. Estes dados permitem supor que pode haver cepas com resistência a uma ou mais drogas antiparasitárias, decorrente da utilização de tratamento supressivo e da rápida alternância de bases químicas no Jockey Clube.

Muito embora as lactonas macrocíclicas sejam endectocidas de grande eficácia, existem relatos de resistência do $\boldsymbol{P}$. equorum frente a ivermectina e a moxidectina. Ambas as drogas foram testadas em dois Haras de cavalos PSI na região de Ontário, Canadá com histórico de resistência dos pequenos estrôngilos ao fenbendazole e ao pirantel. Os resultados revelaram um percentual de redução no OPG do $\boldsymbol{P}$. equorum de 22,6 e 39,1\% para o ivermectin e de 40,5 e 53,5\% para o moxidectin (SLOCOMBE, 2002). Adeterminação mais surpreendente é que a moxidectina nunca tinha sido utilizada nestas propriedades anteriormente. HEARN \& PEREGRINE (2003) determinaram altas contagens de ovos de $\boldsymbol{P}$. equorum 13 dias após o tratamento de 11 potros com ivermectin também no Canadá. O rebanho analisado apresentava histórico de tratamento exclusivo com esta droga por um período maior que 10 anos. Como a resistência nesta espécie de parasita é rara, os autores suspeitam que a cepa resistente possa ter sido introduzida após a aquisição de um grupo de 16 animais meses antes do teste clínico. BOERSEMA e colaboradores (2002) também evidenciaram a falha total da ivermectina (30\%) e moxidectina (0\%) em reduzir o número de ovos de $\boldsymbol{P}$. equorum. Neste mesmo trabalho o pamoato de pirantel obteve redução de $90,4 \%$ contra o mesmo organismo. Entretanto, dois rebanhos foram avaliados e o ivermectin demonstrou alta eficácia (acima de 94\%) contra o P. equorum e várias outras espécies de parasitas (KLEI et al., 2001). KAPLAN et al. (2003) determinaram que a eficácia de fenbendazole, oxibendazole, pirantel, e ivermectina contra 
cyathostominos foi de 31, 69, 73 e acima de 99\%, respectivamente. Estes dados foram colhidos em cinco estados norte-americanos, sugerindo que a resistência só não é prevalente contra a ivermectina.

Embora com comprovações variáveis e discutíveis, o desenvolvimento da resistência a ivermectina em cyathostominos ainda é insignificante, mesmo após 20 anos de uso intensivo desta molécula. Talvez haja possibilidade de ocorrência de sua ineficácia contra cyathostominos encistados. E como entre 10 a $95 \%$ dos parasitas se encontra nesta fase durante o verão, as formas encapsuladas se apresentariam como a população em refugia, retardando o desenvolvimento da resistência contra esta macrolactona (COLES et al., 2003).

Como retardar o processo da resistência - controle integrado

Atualmente a principal forma de controle parasitário se baseia exclusivamente no uso constante de compostos antiparasitários. A possibilidade de integrar outras formas de controle parasitário tem o objetivo de reduzir o número de larvas infectantes na pastagem e o número de tratamentos antiparasitários e ainda diminuir o grau de infecção parasitária nos animais. Pode-se obter bons resultados com a combinação de duas ou mais estratégias com o objetivo de retardar o desenvolvimento da resistência parasitária:

Freqüencia/época do tratamento: Devese propor um calendário que promova ótimo controle parasitário com o menor número de tratamentos possível, a fim de otimizar a utilização dos compostos antiparasitários. Uma boa maneira de esclarecer tal questionamento é saber identificar e monitorar os parasitas presentes através do exame de OPG rotineiramente a cada 90 a 120 dias. O intervalo entre tratamentos pode ser estipulado através da determinação do período de reaparecimento dos ovos (PRO). Este modelo pode ser definido como o intervalo entre o tratamento e o momento que o OPG do grupo tratado apresenta média de 200 ou mais ovos.

Escolha do medicamento: Deve-se utilizar somente compostos que tenham eficácia comprovada nas dosagens recomendadas. Drogas com grande poder residual têm a desvantagem de selecionar organismos dominantes (RR). Quando possível, devese optar por compostos de eficácia comprovada e de curto poder residual. As sub-dosagens não devem ser encaradas como fator de seleção, visto que permitem a sobrevivência de organismos heterozigotos (SR e RS), o que retarda o aparecimento da resistência parasitária (BARNES \& DOBSON, 1990). Sugere-se cautela quanto à utilização da moxidectina para eliminar larvas encistadas, devido ao risco de produzir resistência as demais lactonas macrocíclicas.

Alternância das bases químicas: Em eqüinos é impossível pensar em utilizar uma única base química ano após ano devido a grande variação de gêneros de parasitas presentes. Recomenda-se proceder com três ou quatro tratamentos com uma base química e mais um com outra de mecanismo de ação diferente (3+1). Desta forma o processo de seleção parasitária será reduzido consideravelmente. Quando uma nova alternância for necessária, deve-se optar por um composto de classe diferente e não compostos que compartilhem o mesmo mecanismo de ação.

Mistura de compostos - combinação: Uma das várias formas de melhor utilização dos compostos antiparasitários é a combinação de drogas. Esta estratégia é utilizada após o aparecimento da resistência a um grupo de drogas e/ou para ampliar o espectro de ação do produto final (Tabela 1). A combinação dificulta o aparecimento de genes da resistência e apresenta reduzido potencial para difundir esta característica na população parasitária. No entanto é fundamental que os compostos apresentem, isoladamente, eficácia acima de 95\%. Se caso uma droga já apresente eficácia reduzida, o processo de seleção será acelerado para o composto de eficácia alta.

Tratamento seletivo: Este tratamento deve ser instituído somente quando a contagem individual ultrapassar 200 OPG. A estratégia de tratamento seletivo tem o objetivo de medicar os animais infectados com mais chances de eliminar ovos e contaminar a pastagem. Por outro lado, preserva uma porção da população de hospedeiros que não receberão tratamento, sendo estes responsáveis pela eliminação de ovos susceptíveis na pastagem e manutenção da refugia.

Manejo da propriedade: Deve-se associar mais de uma estratégia de manejo com o intuito de reduzir o número de formas infectantes no meio ambiente. Incluindo: tratar os animais somente após mover para pastagem limpa (MOLENTO et al., 2004), utilizar animais de espécies diferentes no mesmo pasto, plantar culturas estacionais em intervalos anuais, remover as fezes do ambiente duas vezes por semana e gradear o pasto para fragmentação do bolo fecal e dessecação de ovos ou larvas. Estão sendo estudadas outras formas de controle parasitário utilizando fungos nematófagos e vacinas.

\section{CONCLUSÃO}

Existem inúmeros relatos da redução de atividade dos compostos antiparasitários em eqüinos 
no Brasil, revelando uma situação tão alarmante quanto a que atualmente ocorre em ovinos e bovinos. Agora a grande preocupação é a suspeita da resistência do $\boldsymbol{P}$. equorum às macrolactonas. Para mudar este panorama, é necessário, antes de tudo, alterar o conceito de erradicação, voltando esforços para um combate eficiente. A dependência na utilização de antihelmínticos deve ser repensada, do tradicional calendário planejado ao tratamento individualizado, reservando drogas com poder larvicida para animais clinicamente positivos (COLES et al., 2003).

Deve-se ter em mente que é mais produtivo, inclusive economicamente, prevenir a doença ao invés de eliminá-la, mantendo um baixo grau de infecção no animal e na pastagem. A preservação da refugia deve ser o objetivo de todo controle parasitário.

É necessário que a informação científica chegue ao técnico de campo e este seja alertado a observar fatores como a epidemiologia, o tratamento estratégico e/ou seletivo, a higiene das pastagens e a escolha correta do produto. Além destes, é crucial que se realize teste de eficácia duas vezes ao ano para prevenir mais eficazmente o desenvolvimento da resistência. O objetivo é propor medidas de manejo que sejam viáveis na sua aplicação e sustentáveis em logo prazo.

\section{REFERÊNCIAS}

ALMEIDA, G. et al. Freqüência de tratamento antiparasitário e falta de eficácia em helmintos de eqüinos PSC no Jockey Club de Santa Maria, RS. Revista Brasileira de Parasitologia Veterinária, v.13, supl.1, p.274, 2004.

BARBOSA, O.F. et al. A survey on Cyathostominae nematodes (Strongylidea, Strongylidae) in pasture bred horses from São Paulo State, Brazil. Semina: Ciências Agrárias, v.22, p.2126, 2001.

BARGER, I.A. Control strategies minimizing the use of anthelmintics. In: SEMINÁRIO DE OVINOS E BOVINOS, 25., 1995, Palmerston North. Publicação n. 165. Nova Zelândia: Veterinary Continuing Education, Massey University, Palmerston North, 1995. p.59-66.

BARNES, E.H.; DOBSON, R.J. Population dynamics of Trichostrongylus colubriformis in sheep: computer model to simulate grazing systems and the evolution of anthelmintic resistance. International Journal of Parasitology, v.20, p.823-831, 1990 .

BARRETT, E.J. et al. Field trial of the efficacy of a combination of ivermectin and praziquantel in horses infected with roundworms and tapeworms. Veterinary Record, v.184, p.323-325, 2004.

BOERSEMA, J.H. et al. Apparent resistance of Parascaris equorum to macrocyclic lactones. Veterinary Record, v.150, p.279-281, 2002.
CHAPMAN, M.R. et al. Identification and characterization of a pirantel pamoate resistant cyathostome population. Veterinary Parasitology, v.66, p.205-212, 1996.

COLES, G.C. et al. World association for the advancement of veterinary parasitology (WAAVP) methods for the detection of anthelmintic resistance in nematodes of veterinary importance. Veterinary Parasitology, v.44, p.35-44, 1992.

COLES, G.C. et al. Anthelmintic resistance and the use of anthelmintics in horses. Veterinary Record, v.162, p.636, 2003.

CONDER, G.A.; CAMPBELL, W.C. Chemotherapy of nematode infections of veterinary importance, with special reference to drug resistance. Advances in Parasitology, v.35, p.1-83, 1995.

DI PIETRO, J.A. Daily anthelmintics therapy in horses. Compendium on Continuing Education for the Practicing Veterinarian, v.6, p.651-654, 1992.

DUNCAN, J.L. et al. World association for the advancement of veterinary parasitology (WAAVP): second edition of guidelines for evaluating the efficacy of equine anthelmintics. Veterinary Parasitology, v.103, p.118, 2002.

ENGRACIA, J.R. et al. Eficácia da associação ivermectina e praziquantel, em formulação gel, contra endoparasitos de eqüinos (Eqqus caballus). ARS Veterinaria, v.15, p.29-33, 1999.

HEARN, F.P.D.; PEREGRINE, A.S. Identification of foals infected with Parascaris equorum apparently resistant to ivermectin. Journal of the American Veterinary Medicine Association, v.223, p.482-485, 2003.

KAPLAN, R.M. et al. Prevalence of anthelmintic resistance on horse farms in the southern United States. In: WAAVP, 19., 2003, New Orleans, USA. Anais... New Orleans: WAAVP, 2003. 262p. p.126.

KLEI, T.K.; CHAPMAN, M.R. Immunity in equine cyathostome infections. Veterinary Parasitology, v.85, p.123-136, 1999.

KLEI, T.R. et al. Re-evaluation of ivermectin efficacy against equine gastrointestinal parasites. Veterinary Parasitology, v.98, p.315-320, 2001.

LYONS, E.T. et al. Critical tests of three salts of pirantel against internal parasites of the horse. American Journal of Veterinary Research, v.35, p.1515-1522, 1974.

MARTIN, R.J. Modes of action of anthelmintic drugs. Veterinary Journal, v.154, p.11-34, 1997.

MERCADANTE, A. et al. Ocorrência de resistência aos antihelmínticos em eqüinos Puro-Sangue, na região metropolitana de Curitiba. Revista Brasileira de Parasitologia Veterinária, v.6, p.246, 1997.

MERCIER, P. et al. Comparative efficacy, persistent effect, and treatment intervals of anthelmintic pastes in naturally infected horses. Veterinary Parasitology, v.99, p.29-39, 2001. 
MOLENTO, M.B. et al. Sustainable worm management. Veterinary Record, v.171, p.95-96, 2004.

MONAHAN, C.M. et al. Comparison of moxidectin oral gel and ivermectin oral paste against a spectrum of internal parasites of ponies with special attention to encysted cyathostome larvae. Veterinary Parasitology, v.63, p.225235, 1996

PRESLAND, S.L. et al. Counting nematode eggs in equine faecal samples. Veterinary Record, v.156, p.208-210, 2005 .

PRICHARD, R.K. Genetic variability following selection of Haemonchus contortus with anthelmintics. Trends in Parasitology, v.17, p.445-453, 2001.

REHBEIN, S. et al. Field efficacy of ivermectin plus praziquantel oral paste against naturally acquired gastrointestinal nematodes and cestodas of horses in North America and Europe. Veterinary Therapeutics, v.4, p.220227, 2003.

SABATINI, G.A. et al. Ação endoparasiticida do abamectin associado ao praziquantel para eqüinos. ARS Veterinaria, v.15, p.40-44, 1999.

SANGSTER, N.C. Pharmacology of anthelmintic resistance in cyathostomes: will it occur with the avermectin/ milbemycins? Veterinary Parasitology, v.85 p.189-204, 1999.

SANGSTER, N.C. A practical approach to anthelmintic resistance. Equine Veterinary Journal, v.35, p.218-219 2003.
SLOCOMBE, O. Clinical trials for anthelmintic resistance in Parascaris equorum on stud farms in Southwestern Ontario. Ontário: Departamento de Patobiologia do Colégio de Veterinária de Ontário, 2002. 15p.

SUTHERST, R.W.; COMINS, H.N. The management of acaricide resistance in the cattle tick, Boophilus microplus (Canestrini) (Acari: Ixodidae), in Australia. Bulletin of Entomology Research, v.69, p.519-537, 1979.

TANCREDI, I.P. et al. Eficácia do ivermectin e praziquantel pasta no controle de infecções por cestódeos em eqüinos. Hora Veterinária, v.119, p.29-32, 2001.

TANCREDI, I.P. et al. Eficácia anti-helmíntica de dois compostos em gel, via oral, no controle de endoparasitos em eqüinos. Revista Brasileira de Parasitologia Veterinária, v.13, supl.1, p.296, 2004.

TODD, A.C. et al. Continuous phenothiazine therapy in horses. Part I. Effect on the worm parasite. Veterinary Medicine. v.44, p.411-414, 1949.

YOUNG, K.E. et al. Parasite diversity and anthelmintic resistance in two herds of horses. Veterinary Parasitology, v.85, p.205-214, 1999.

VAN WYK, J.A. Refugia - overlooked as perhaps the most potent factor concerning the development of anthelmintic resistance. Onderstepoort Journal of Veterinary Research, v.68, p.55-67, 2001.

$\mathrm{XU}, \mathrm{M}$. et al. Ivermectin resistance in nematodes may be caused by alteration of P-glycoprotein homolog. Molecular and Biochemical Parasitology, v.91, p.327-335, 1998. 